University of Montana

ScholarWorks at University of Montana

\title{
Assessing the Performance of Sampling Designs for Measuring the Abundance of Understory Plants
}

\author{
Ilana L. Abrahamson \\ University of Montana - Missoula \\ Cara R. Nelson \\ University of Montana - Missoula \\ David L.R. Affleck \\ University of Montana - Missoula
}

Follow this and additional works at: https://scholarworks.umt.edu/forest_pubs

Part of the Forest Management Commons

Let us know how access to this document benefits you.

\section{Recommended Citation \\ Ilana L. Abrahamson, Cara R. Nelson, and David L. R. Affleck 2011. Assessing the performance of sampling designs for measuring the abundance of understory plants. Ecological Applications 21:452-464. http://dx.doi.org/10.1890/09-2296.1}

This Article is brought to you for free and open access by the Forest Management at ScholarWorks at University of Montana. It has been accepted for inclusion in Forest Management Faculty Publications by an authorized administrator of ScholarWorks at University of Montana. For more information, please contact scholarworks@mso.umt.edu. 


\title{
Assessing the performance of sampling designs for measuring the abundance of understory plants
}

\author{
Ilana L. Abrahamson, ${ }^{1}$ Cara R. Nelson, and David L. R. Affleck
}

College of Forestry and Conservation, University of Montana, 32 Campus Drive, Missoula, Montana 59812

\begin{abstract}
Accurate estimation of responses of understory plants to disturbance is essential for understanding the efficacy of management activities. However, the ability to assess changes in the abundance of plants may be hampered by inappropriate sampling methodologies. Conventional methods for sampling understory plants may be precise for common species but may fail to adequately characterize abundance of less common species. We tested conventional (modified Whittaker plots and Daubenmire and point-line intercept transects) and novel (strip adaptive cluster sampling [SACS]) approaches to sampling understory plants to determine their efficacy for quantifying abundance on control and thinned-and-burned treatment units in Pinus ponderosa forests in western Montana, USA. For species grouped by growth-form and for common species, all three conventional designs were capable of estimating cover with a $50 \%$ relative margin of error with reasonable sample sizes (3-36 replicates for growth-form groups; 8-14 replicates for common species); however, increasing precision to $25 \%$ relative margin of error required sample sizes that may be infeasible (11-143 replicates for growthform groups; 28-54 replicates for common species). All three conventional designs required enormous sample sizes to estimate cover of nonnative species as a group (29-60 replicates) and of individual less common species (62-118 replicates), even with a $50 \%$ relative margin of error. SACS was the only design that efficiently sampled less common species, requiring only $6-11 \%$ as many replicates relative to conventional designs. Conventional designs may not be effective for estimating abundance of the majority of forest understory plants, which are typically patchily distributed with low abundance, or of newly establishing nonnative plants. Novel methods such as SACS should be considered in investigations when cover of these species is of concern.
\end{abstract}

Key words: adaptive cluster sampling; Daubenmire transect; forest restoration; modified Whittaker plot; nonnative plants; point-line intercept; sample size; sampling efficiency; understory vegetation.

\section{INTRODUCTION}

Ecologists and managers devote a considerable amount of attention to measuring responses of understory plants to natural disturbances and management activities (e.g., Fulé et al. 2005, Metlen and Fiedler 2006, Nelson et al. 2008). Their ability to adequately assess vegetation responses, however, is based on the capabilities of the sampling methods employed. Most conventional methods were designed to classify vegetation types by characterizing the abundance of common species (Thompson 2004) in relatively homogenous environments (MuellerDombois and Ellenburg 1974, Barnett and Stohlgren 2003). Thus, they may be adequate for providing estimates of mean abundance of dominant plants or grouped growth forms (e.g., graminoids or forbs), but may not adequately estimate abundance of less common, heterogeneously distributed plants (those

Manuscript received 21 December 2009; revised 30 April 2010; accepted 4 May 2010. Corresponding Editor: T. J. Stohlgren.

${ }^{1}$ E-mail: i_abrahamson@yahoo.com with low local abundances or clumped spatial patterns). These less abundant species comprise the majority of the flora in forest ecosystems and frequently are of greatest management concern (Korb et al. 2003). Furthermore, while plant communities are generally characterized by the dominant vegetation, there is increasing interest in understanding patterns of abundance of locally uncommon invasive plants and rare native plants in heterogeneous environments. For instance, at early stages of invasion, nonnative plants may occur at low frequency; however, it is during this time period that their detection may be most critical for effective management (Rejmanek 2000). For species that are locally uncommon, it is particularly important to use a sampling strategy that will precisely estimate cover, whereas for common species that do not require management action, a less precise estimate of cover may suffice. Increasing or maintaining diversity and abundance of native plants and reducing abundance of nonnative invasive taxa are common objectives of forest restoration treatments (Wienk et al. 2004, Metlen and Fiedler 2006; Society for Ecological Restoration International primer for ecological resto- 
ration, version 2 [2004; available online]). ${ }^{2}$ However, not enough attention has been devoted to assessing the efficacy of sampling methods for measuring their responses to disturbance and management (but see Korb et al. 2003 and Abella and Covington 2004).

Many plant communities are composed of relatively few dominant (i.e., high relative abundance) plants, with the majority of species occurring at low abundance (Stohlgren et al. 1998, Abella and Covington 2004) and with heterogeneous spatial distributions (Greig-Smith 1983, Goslee 2006). The distribution of these less common, spatially aggregated plants is driven by forest resources, such as light, water, and soil nutrients, that occur unevenly within forest stands (Barbier 2008), due to within-stand heterogeneity in structure, composition, and abiotic conditions. For instance, understory light availability depends on the spatial arrangement and composition of canopy and subcanopy trees (Miller et al. 2002, Barbier 2008); thus, variation in tree density, height, composition, and canopy openness create a mosaic of understory light patterns (Scheller 2002, Moora et al. 2007). In addition, soil nutrients and moisture are patchily distributed within forest stands (Miller et al. 2002). Disturbances also add heterogeneity; stands that have been burned or thinned generally contain a mosaic of disturbance intensities (Turner et al. 1997, Knapp and Keeley 2006, Baker et al. 2007). Accordingly, patterns in understory vegetation are driven by within-stand heterogeneity of resources. For instance, ruderal, fire-adapted native and nonnative invasive plants may peak in abundance in forest openings and disturbed pockets (Griffis et al. 2001, Fulé et al. 2005), while undisturbed areas may serve as refugia for late-seral herbs (Turner et al. 1997, Nelson and Halpern 2005, Knapp et al. 2007). Selection of sampling designs must be based on the spatial structure and heterogeneity of the overall plant community or the species of management concern (Barnett and Stohlgren 2003, Goslee 2006, Stohlgren 2007). Designs that do not capture the patchy nature of less common plants, including invading nonnatives, may not be the most appropriate measurement strategies for assessing responses to disturbance.

Conventional sampling designs - i.e., those commonly reported in the ecological literature or used by federal land management agencies such as USDI National Park Service (2003) or USDA Forest Inventory and Analysis National Program (2007; available online $)^{3}$-as implemented may not adequately estimate abundance of less common plants due to low within-stand replication and total area sampled and, consequently, limited plot distribution. Given constraints in funding and sampling time, there are trade-offs between size of sample plots, total number of plots, and their distribution within

\footnotetext{
${ }^{2}\langle$ http://www.ser.otg/cibtebt/ecological_restoration_primer. asp $\rangle$

${ }_{3}^{3}$ http://www.fia.fs.fed.us/library/field-guides-methods-proc〉
}

study stands. For example, methodologies that include large plots (e.g., modified Whittaker) are costly in terms of sampling time and, therefore, plot replication is generally limited (Barnett and Stohlgren 2003, Stohlgren 2007). Consequently, plots are not well distributed, and species that are aggregated or occur at low abundance are likely to be missed or underrepresented. In addition, limited replication associated with time-intensive designs may result in low statistical power for detecting differences in abundance of individual species. Conversely, designs such as point-line intercept that sample a very small area are relatively fast to employ (Abella and Covington 2004) and can allow for considerable replication. Highly replicated point-line intercept transects have been shown to quantify total plant cover with greater precision than other designs (Floyd and Anderson 1987); however, they may not adequately characterize the abundances of individual species, especially those that are uncommon, due to limited spatial support (Stohlgren et al. 1998, Korb et al. 2003).

Although the comparative performance of sampling strategies has received considerable attention (e.g., Mueller-Dombois and Ellenberg 1974 Stohlgren et al. 1998, Korb et al. 2003, Abella and Covington 2004, Huebner 2007), previous investigations have not compared the efficacy of designs for characterizing abundance of understory species that vary widely in abundance and spatial pattern (e.g., common plants vs. those that are less common and spatially aggregated), nor have they assessed relative efficiencies of designs in terms of required sample sizes and time to sample. Finally, most previous investigators (e.g., Stohlgren et al. 1998, Goslee 2006, Huebner 2007) did not control for sampling time (but see Korb et al. 2003, Abella and Covington 2004); thus, interpretations about the efficacy of methods are confounded with time devoted to each method.

We examined the performance of sampling designs for estimating the cover and frequency of species of varying abundance in forest stands with differing management histories. Specifically, we assessed the strengths and limitations of three conventional multispecies methods (Daubenmire transects, modified Whittaker plots, and point-line intercept transects) and one method designed for measuring individual target species (strip adaptive cluster sampling [SACS]), in order to address the following questions: (1) Do estimates of mean abundance of total vegetation, vegetation grouped by growth form (graminoid, forb, or shrub) or origin (native vs. nonnative), and individual species vary based on the sampling design employed? (2) Is there variation among designs in the required sample sizes and time-to-sample for estimating mean cover of total vegetation, of vegetation grouped by growth form or origin, and of individual species? (3) Do designs perform differently for common vs. less common plants? 
a) Point-line intercept transect

$\downarrow \downarrow \downarrow \downarrow \downarrow \downarrow \downarrow \downarrow \downarrow \downarrow \downarrow \downarrow \downarrow \downarrow \downarrow \downarrow \downarrow \downarrow \downarrow \downarrow \downarrow \downarrow \downarrow \downarrow \downarrow \downarrow \downarrow \downarrow \downarrow \downarrow \downarrow \downarrow \downarrow \downarrow \downarrow \downarrow \downarrow \downarrow \downarrow \downarrow \downarrow \downarrow \downarrow \downarrow \downarrow \downarrow \downarrow \downarrow \downarrow \downarrow \downarrow \downarrow \downarrow \downarrow$

b) Daubenmire transect

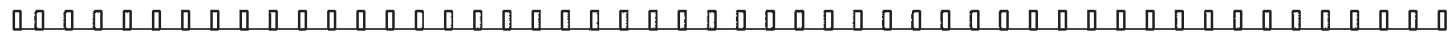

c) Modified Whittaker plot

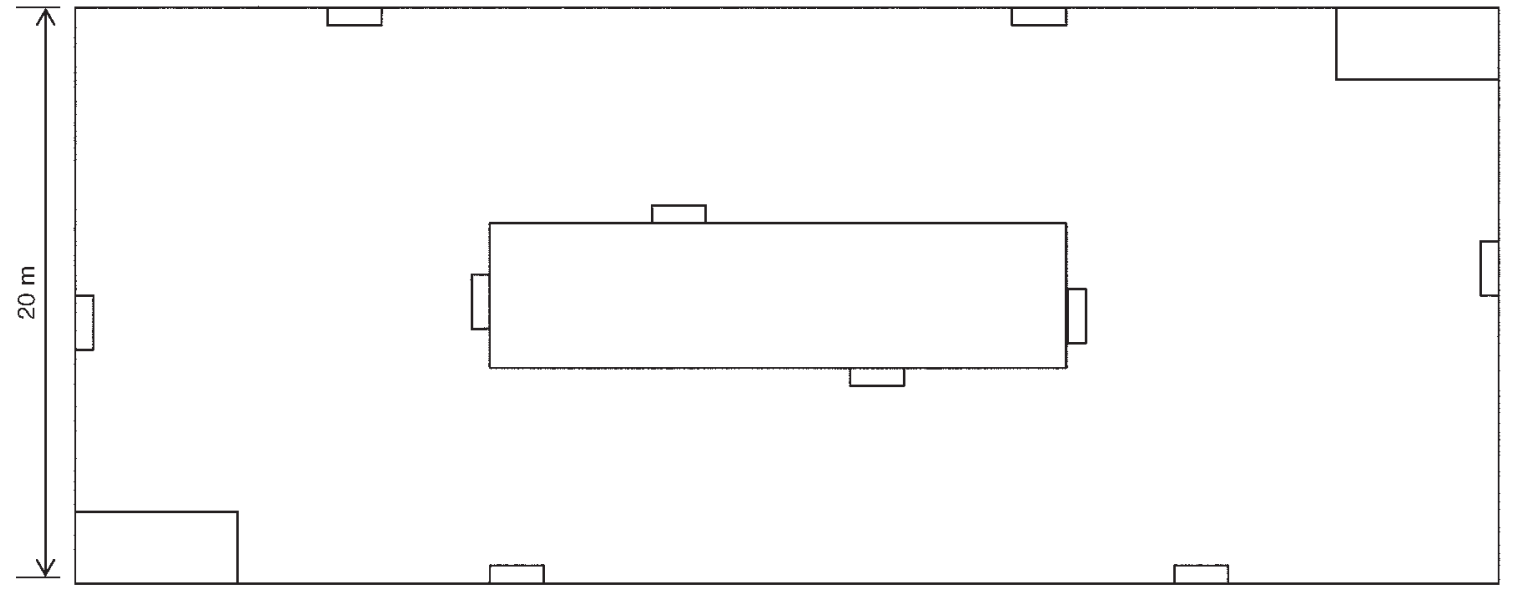

d) Strip adaptive cluster sampling

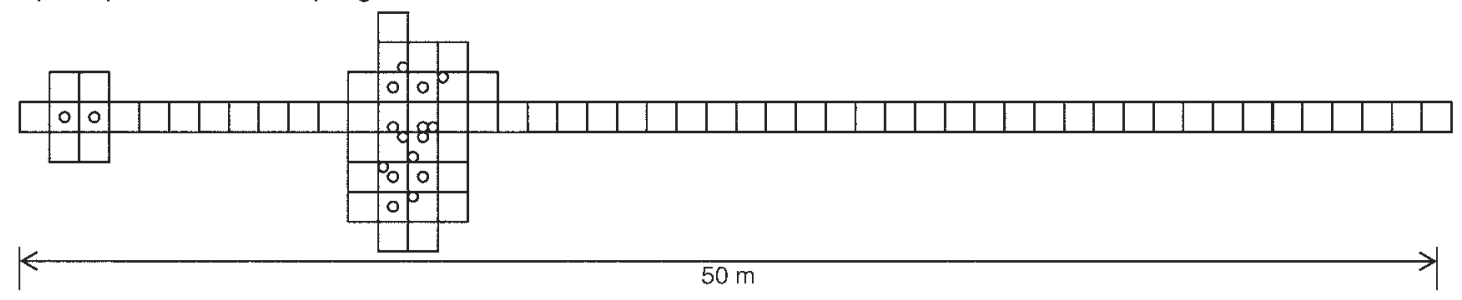

FIG. 1. The four sampling designs tested for estimating cover of forest understory plants in western Montana, USA: (a) pointline intercept transect, 166 points spaced every $30 \mathrm{~cm}$; (b) Daubenmire transects, fifty $20 \times 50 \mathrm{~cm}$ subplots; (c) modified Whittaker plots, ten $1-\mathrm{m}^{2}$ quadrats, two $10-\mathrm{m}^{2}$ subplots, one $100-\mathrm{m}^{2}$ subplot, within full $20 \times 50 \mathrm{~m}$ plot; (d) strip adaptive cluster sampling initial transect, fifty $1 \times 1 \mathrm{~m}$ subplots.

\section{Methods \\ Study site}

This study was conducted at the University of Montana's 11 000-ha Lubrecht Experimental Forest in western Montana, USA $\left(47^{\circ} \mathrm{N}, 113^{\circ} \mathrm{W}\right)$. The mean annual temperature is $7^{\circ} \mathrm{C}$, and the mean annual precipitation is $55 \mathrm{~cm}$-nearly half falling as snow (Nimlos 1986). Sample stands range from $1263 \mathrm{~m}$ to $1388 \mathrm{~m}$ in elevation and are dominated by secondgrowth Pinus ponderosa and Pseudotsuga menziesii. Dominant understory graminoids include Calamagrostis rubescens and Carex geyeri, dominant shrubs include Symphorocarpus albus, Mahonia repens (Lind1.) G. Don, and Spirea betulifolia, and dominant forbs include Achillea millifolium, Antennaria spp., and Arnica cordifolia. Nomenclature follows Hitchcock and Cronquist (1973), except where naming authority is given.
Sampling was conducted on experimental units that were previously established to evaluate effects and efficacy of forest restoration treatments on numerous ecosystem variables including understory vegetation (see Metlen and Fiedler [2006] for a description). We sampled three 9-ha thinned-and-burned stands, as well as three 9-ha untreated control stands, in order to capture the greatest range in abundance of individual species.

\section{Field sampling}

During summer 2008, at each of the six stands, data were collected on total vegetation cover, individual species cover for 24 understory plants, species richness, and time required to collect data, using each of the following four sampling designs (Fig. 1):

1) Point-line intercept transect, PLIT ( $n=16$ transects/treatment unit), commonly used by U.S. federal agencies to sample understory cover (e.g., 
USDI National Park Service 2003). We sampled 50-mlong transects, with points spaced every $30 \mathrm{~cm}(n=166$ points/transect). At each point, we lowered a vertical projection and recorded vegetation that was contacted. The proportion of points that intercept a particular species equals that species' cover (Greig-Smith 1983).

2) Daubenmire transect, DT $(n=16$ transects/ treatment unit), widely used to estimate plant cover in a variety of ecological systems (e.g., Daubenmire 1959, Halpern et al. 2005, Nelson et al. 2008). Foliar cover is visually estimated by cover class, in systematically spaced quadrats along multiple transects. We used 50$\mathrm{m}$ transects with $50,20 \times 50$-cm quadrats spaced every meter.

3) Modified Whittaker plot, MWP ( $n=8$ plots/ treatment unit), advocated for measuring community diversity (Shmida 1984, Stohlgren et al. 1995), but are also widely employed to measure abundance of individual species. This design utilizes a $20 \times 50 \mathrm{~m}$ multi-scale plot composed of nonoverlapping subplots. Within the $20 \times 50 \mathrm{~m}$ plot, $101-\mathrm{m}^{2}$ quadrats are sampled for species richness and cover; in addition, species presence is recorded in two $10-\mathrm{m}^{2}$ subplots, one $100-\mathrm{m}^{2}$ subplot, and the full plot (see Stohlgren et al. 1995).

4) Strip adaptive cluster sampling, SACS ( $n=16$ initial transects/treatment unit), suggested to improve detection of species that are low in abundance and spatially aggregated (e.g., burgeoning invaders or less common native plants) (Thompson 2002, Brown 2003). However, this method is infrequently reported in the plant ecology literature (but see Acharya et al. 2000, Philippi 2005), and standard texts on vegetation sampling (e.g., Mueller-Dombois and Ellenberg 1974, Greig-Smith 1983) predate adaptive sampling designs. When a specified cover or density (the critical value) of a focal species is detected within a quadrat, additional quadrats are sampled surrounding the initial quadrat, thus characterizing the clustering nature of species. The number of adaptively added quadrats will vary, according to rate of detection of particular species. We used a contiguous transect of $50,1 \times 1 \mathrm{~m}$ quadrats (i.e., $1 \times 50$ $m$ belt) as the first phase of SACS (Thompson 1991). For each $1-\mathrm{m}^{2}$ quadrat in which a target species was detected at or above the critical value, the four $1-\mathrm{m}^{2}$ quadrats that directly bordered the sampled quadrat were added to the sampling area for that species (i.e., adaptively added neighborhoods consisted of four $1-\mathrm{m}^{2}$ quadrats in a cross pattern; Fig. 1d). Successive quadrats were sampled using the same neighborhood rules, until the target species was not found at the critical value.

In order to allocate similar amounts of time to each design, we sampled half as many MWPs (which are time consuming to measure) on each treatment unit as we did for faster-to-sample transect-based designs (PLIT, DT, and SACS). Because of the substantial amount of time required to establish MWPs, we did not install all of the MWPs but rather sampled 7 randomly selected plots of the 10 plots already established (Metlen and Fiedler
2006). In addition, we installed (and sampled) one additional MWP/treatment unit, in order to determine plot-establishment time.

In order to minimize variation in sampling locations among designs, we located eight of the PLIT, DT, and SACS transects along one 50 -m side of each of the eight MWPs (see Appendix A for figure). The remaining eight transects for each transect-based design were located using methods similar to the previously established MWPs (Metlen and Fiedler 2006).

Twenty-four focal plants, representing a range of origins, abundances, and distribution patterns, were selected for abundance measurements based on observed distributions at our sites (Metlen and Fiedler 2006) and degree of management concern (Appendix C). Eight of the species were included because they occur on statelevel noxious weed lists in the northwestern United States (USDA NRCS 2008) or have potential to cause extensive ecological damage (e.g., Bromus tectorum; D'Antonio and Vitousek 1992).

The total vegetative cover, as well as the cover and frequency of each focal species, was sampled using the three methods designed to measure multiple species (DT, MWP, and PLIT). We also used SACS to measure two native (Heuchera cylindrica and Smilacina racemosa) and two nonnative (Bromus tectorum and Cirsium arvense) plants that show highly clustered distributions. The critical values used for SACS were: one individual for $C$. arvense and $S$. racemosa; $0.5 \%$ cover for $B$. tectorum; and $1 \%$ cover for H. cylindrica.

Data were collected between 5 June and 3 August 2008, after plants had fully leafed out and before latesummer desiccation. The order that sites were sampled, as well as the order of sampling designs at each site, was random. Resolution for ocular estimates of percent cover was nearest $0.1 \%$ for $<1 \%, 1 \%$ for $1-10 \%$, and $5 \%$ for $>10 \%$. To reduce observer error and bias, data were collected by only two well-trained individuals, and estimations between observers were calibrated regularly. In addition to collecting vegetation data, observers recorded the amount of time spent sampling, including time spent traveling between plots, surveying plot boundaries, and estimating species' cover. For each design (i.e., plot or transect type), a comprehensive survey of all vascular plants was conducted on one randomly selected plot or transect per treatment unit; for this plot or transect, species cover was collected for all species (not just the target species) in order to determine the time required to sample all vascular plants present.

\section{Statistical analysis}

For each design and treatment unit, we calculated mean cover for total vegetation, for species grouped by growth form (graminoids, forbs, shrubs) and origin (native and nonnative), and for individual focal species. Grouped vegetation variables (i.e., species grouped by growth form and origin) only included data for the relevant 24 focal species, not for the plant community 
overall. For DT, MWP and PLIT, mean cover was first calculated at the transect or plot level; these transect- or plot-level data were then used to compute stand-level means and standard deviations. For SACS, stand-level mean cover and variances for individual species were estimated from the approximately unbiased equations:

$$
\begin{aligned}
\hat{\mu} & =\frac{1}{n} \sum_{i}\left(\frac{1}{50} \sum_{j} \tilde{y}_{i j}\right) \\
\widehat{\operatorname{var}}(\hat{\mu}) & =\frac{N-n}{N n(n-1)} \sum_{i}\left[\left(\frac{1}{50} \sum_{j} \tilde{y}_{i j}\right)-\hat{\mu}\right]^{2}
\end{aligned}
$$

where $i$ and $j$ index strips and quadrats, respectively; $n$ is the number of strips per stand (16); $N$ is the number of possible strips per stand (300); and

$$
\tilde{y}_{i j}=\frac{\sum_{l}\left(\text { cover value }_{l}\right)}{\text { network size }}
$$

with the sum taken over all $1-\mathrm{m}^{2}$ cells of the network to which quadrat ${ }_{i j}$ belongs (Appendix C). Stand-level frequency was calculated for each of the focal species for each design as percentage of transects or plots within a stand containing the focal species. Constancy was calculated as number of treatment units on which a species was found.

Statistical tests for among-sampling-design differences in species cover were not possible, due to unequal variances among designs. However, effects of sampling design, environment (treated vs. control), and their interaction on within-stand standard deviations of measurements of cover were assessed using split-plot ANOVA (Ott and Longnecker 2001), with design and environment as fixed effects and geographic block, stand, and sampling location as random effects. Separate tests were performed for cover of total vegetation, grouped vegetation variables (graminoids, forbs, and shrubs; and native and nonnative plants), and cover of each focal species for which data met ANOVA conditions. To correct for heteroscedasticity, standard deviations of individual species and grouped vegetation variables were log-transformed. In addition, split-plot ANOVAs with Tukey's hsd post hoc comparisons (Ott and Longnecker 2001) were used to determine whether sampling designs differed in the total amount of time to sample one plot (which included time to establish and take down the plot, sample, and travel between plots).

To assess differences among designs in requirements for replication and time to sample, we calculated the sample size necessary for each design to be within various margins of error (MoE) with $90 \%$ confidence, using the formula

$$
n_{k}=\left[\frac{Z_{0.05} s_{k}}{\mathrm{MoE}}\right]^{2}
$$

where $n_{k}$ is required sample size for design $k, Z_{0.05}=$
1.645 (5th percentile of standard normal distribution), and $s_{k}$ is estimated within-stand standard deviation of design $k$. We calculated the above function for a range of MoE values. In addition, we also determined sample sizes needed to achieve MoE within $25 \%$ and $50 \%$ of the observed means (hereafter, "relative margin of error" or "relative MoE"):

$$
n_{k, 0.25}=\left[\frac{Z_{0.05} s_{k} / \bar{x}_{k}}{0.25}\right]
$$

and

$$
n_{k, 0.5}=\left[\frac{Z_{0.05} s_{k} / \bar{x}_{k}}{0.5}\right]^{2}
$$

where $\bar{x}_{k}$ is the estimated mean cover for design $k$.

For each design, we first determined the required sample sizes independently for each stand on which the species was present and then averaged the resulting values. When sampling designs failed to detect a species within a particular stand (i.e., mean cover $=0$ ), that stand was eliminated from sample size calculations for that particular design.

Sample-size calculations were made for each grouped vegetation variable and species. In addition, we calculated mean sample size requirements for common species $(n=7$ species; species that were present on all six stands and detected with all three multispecies sampling designs) and less common species $(n=17$ species; species that were not detected on all six stands by all three multispecies sampling designs). For grouped vegetation variables and species, we determined time-tosample requirements for each design by multiplying the mean required sample sizes by the mean sampling time observed for that design.

All statistical analyses except sample size calculations were conducted using SPSS, version 15.0 (SPSS 2006).

\section{RESULTS}

\section{Among-design differences in abundance and sampling time}

For grouped vegetation variables, mean cover and standard deviation were always higher for point-line intercept transects (PLITs) than for the other two multispecies designs (Fig. 2). This result was particularly prominent for graminoids: graminoid cover and associated standard deviations were 5 times greater using PLITs than the other two designs. The interaction between design and environment (treated vs. control) was not significant for any of the six grouped vegetation variables; the effect of environment on the within-stand standard deviations of cover was significant for two of the grouped vegetation variables (forbs $F_{1,2}=29.21, P=$ 0.03; and native plants $F_{1,2}=164.57, P=0.006$ ).

For individual common species, PLITs also produced the highest cover and within-stand standard deviation estimates (Fig. 3). However, for less common species, differences among the three multispecies designs could not be detected (Fig. 3). In contrast, for all four species 
sampled with SACS, coefficients of variation were lower with SACS than with other designs (Fig. 4c). While mean cover estimates for SACS were similar to the three multispecies designs, within-stand standard deviation was always lower for SACS (Fig. 4a, b). The interaction between design and environment was not significant for any individual species; in addition, the effect of environment on the within-stand standard deviations of cover was significant for only one of the species tested (Penstemon albertinus $F_{1,2}=465.37, P=0.002$ ).

The frequency of individual species was consistently highest for MWPs $\left(1000 \mathrm{~m}^{2}\right)$, followed by DTs and PLITs, respectively (Fig. 5). While all multispecies designs detected all common species within all six stands, designs differed in their capacity to detect occurrence of less common plants (Fig. 6). Full MWPs $\left(1000 \mathrm{~m}^{2}\right)$ and DTs detected less common species in more stands (4.3 and 3.4, respectively) than did subplots within MWPs $\left(1-\mathrm{m}^{2}\right.$ and $\left.10-\mathrm{m}^{2}\right)$ or PLITs $(2.1,2.4$, and 2.0 stands, respectively) $(P=0.057)$. Not surprisingly, full MWPs also averaged highest richness per plot, followed by DTs and PLITs (57, 28, and 15 species per plot or transect, respectively).

The time to sample one plot differed significantly $(P<$ $0.001)$ by design. For a two-person team to travel to, establish, and sample (all species) at one location, PLITs required on average 52 minutes, DTs 135 minutes, and MWPs 255 minutes. A two-person team required on average 44 minutes to travel, establish, and complete one SACS transect (for one species). We found initial establishment time to be considerable for large, multiscaled MWPs (average of 80 minutes for two people), whereas transect-based designs took on average only 14 minutes for two people to install.

\section{Required sampling effort}

For grouped vegetation variables, PLITs required greater sample sizes than did MWPs or DTs to estimate mean cover within various margins of error (MoE's; Fig. $7 \mathrm{a}-\mathrm{c})$. However, MWP was the most time-intensive design (Fig. 7d-f; Appendix B: Table B1). The required time to sample was similar using PLITs and DTs for all grouped vegetation variables except nonnative cover, for which PLIT was the least time-intensive design (Fig. 7df; Appendix B: Table B1).

For individual species, PLITs required greater sample sizes than MWPs and DTs to estimate mean cover to within various MoEs (Fig. 8a-c). However, to estimate mean cover within $50 \%$ or $25 \%$ of the observed mean (i.e., relative $\mathrm{MoE}$ ), the sample-size requirements varied among designs (because relative $\mathrm{MoE}$ is based on observed mean cover, which varied within a species by design): for a $50 \%$ relative MoE, PLITs required the largest sample size for $46 \%$ of species, and MWPs required the smallest sample size for $67 \%$ (Appendix B). For $63 \%$ of species, the increased precision of MWPs was offset by the longer sampling time required (Appendix B). On the other hand, for $88 \%$ of species

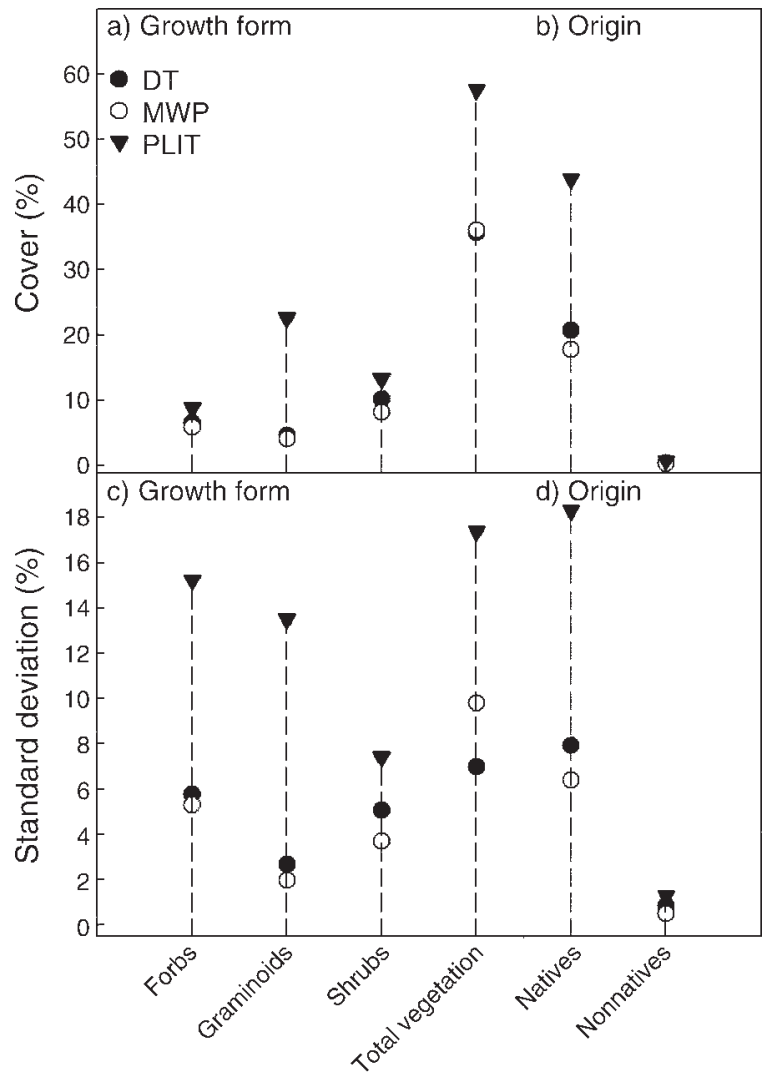

FIG. 2. Sampling results for grouped vegetation variables. $(a, b)$ Percent cover and (c, d) within-stand standard deviation for grouped vegetation variables, by sampling design (DT, Daubenmire transects; MWP, modified Whittaker plots; PLIT, point-line intercept transect). Statistical differences in cover among designs were not assessed (see Methods: Statistical analysis). The statistical significance of tests for differences in standard deviation among designs are: forbs, $F_{2,8}=78.66, P<$ 0.001; graminoids, $F_{2,8}=1060.0, P<0.001$; shrubs, $F_{2,8}=$ $21.95, P=0.001$; total vegetation, $F_{2,8}=2.58, P=0.003$; nonnative vegetation, $F_{2,8}=1.55, P=0.269$; and native vegetation, $F_{2,8}=27.59, P<0.001$.

the greater sample size required by PLITs was offset by the shorter sampling time.

When considering only common species, MWPs required the fewest replicates on average followed by DTs and PLITs $(8,9$, and 14 plots or transects per stand, respectively) to estimate cover within $50 \%$ of the observed mean with $90 \%$ confidence (Table 1). Conversely, for the same level of precision, PLITs required the least amount of time to estimate cover of common species, followed by DTs and MWPs $(12,31$, and 19 hours, respectively). For less common species, of the conventional designs MWPs required the fewest replicates on average, followed by PLITs and DTs (62, 75,118 plots or transects per stand, respectively), to estimate cover within $50 \%$ of the observed mean with 90\% confidence (Table 1). Again, PLITs required the least amount of time to estimate cover for less common species within $50 \%$ of the observed mean, followed by 


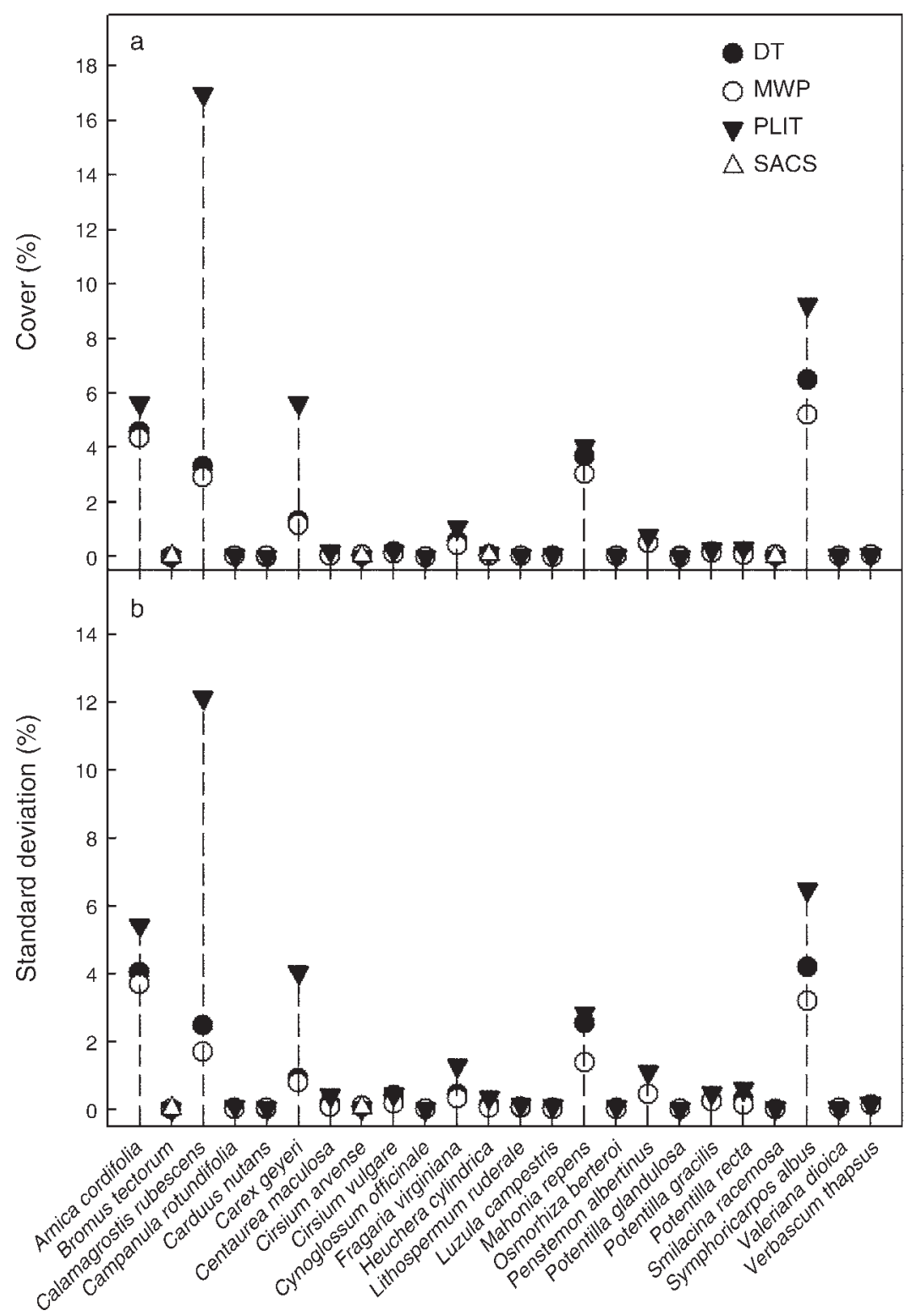

FIG. 3. Sampling results for individual species. (a) Percent cover and (b) within-stand standard deviation for individual species, by sampling design (DT, Daubenmire transects; MWP, modified Whittaker plots; PLIT, point-line intercept transect; SACS, strip adaptive cluster sampling). The statistical significance of tests for differences in standard deviation among designs are: Arnica cordifolia, $F_{2,8}=13.23, P=0.003$; Calamagrostis rubescens, $F_{2,8}=233.35, P<0.001 ;$ Carex geyeri $F_{2,8}=71.75, P<0.001 ;$ Fragaria virginiana, $F_{2,8}=12.44, P=0.004 ;$ Mahonia repens $F_{2,8}=12.40, P=0.004$; Penstemon albertinus, $F_{2,8}=11.51, P=0.004 ;$ and Symphoricarpos albus, $F_{2,8}=11.47, P=0.004$.

MWPs and DTs $(61,246$, and 263 hours, respectively). SACS resulted in enormous gains of efficiency in terms of the sample size required to estimate cover within $50 \%$ or $25 \%$ of the estimated mean, for all four species sampled using this design (Appendix B). SACS time-tosample estimates are not directly comparable to multispecies designs because SACS was implemented separately for individual species rather than for multiple species simultaneously.

\section{DisCusSION}

\section{Among-design differences in abundance and variance}

Sampling strategies intended to unbiasedly estimate mean cover of understory species varied in their efficiency for estimating plant cover. While expected cover estimates should be identical for all sampling designs when coupled with associated unbiased estimators (Gregoire and Valentine 2008), we found that cover of common species differed appreciably, suggesting large 
differences in precision. PLITs (point-line intercept transects) returned cover and standard deviation estimates that were up to 5 times larger than those of DTs (Daubenmire transects) or MWPs (modified Whittaker plots), with graminoids showing the largest magnitude of difference. The higher values of graminoid cover observed with PLITs is consistent with previous studies in forested (Korb et al. 2003) and grassland (Symstad et al. 2008) systems. Plants with long, thin foliage (e.g., graminoid species) are more sensitive to measurement error caused by projection diameters greater than zero and by nonvertical projections (Bonham 1989, Glatzle et al. 1993) and, consequently, may be overestimated by PLITs.

For less common species, it was difficult to detect differences among the three conventional designs in standard deviations of cover estimates, due to low cover estimates and variable occurrences among stands. However, SACS (strip adaptive cluster samples) was much more efficient than the three multispecies designs for estimating cover of these less common, aggregated plants, consistently producing the lowest estimated variances. Coefficients of variations and standard deviations obtained from SACS were always less than half that obtained from the other designs.

We found substantial variation among designs in species' constancy (number of stands) and frequency (number of plots or transects per stand). Although all designs had similar rates of constancy for common species, full MWPs and DTs had higher constancy for less common species than did the smaller modified Whittaker subplots and PLITs. PLITs had the lowest rates of both frequency and constancy for less common plants, which we attribute to the small area sampled. These results are consistent with multiple studies that suggest that large plot sizes may be necessary to detect less common plants (Stohlgren et al. 1998, Korb et al. 2003, Abella and Covington 2004, Symstad et al. 2008).

\section{Required sampling effort}

Although all three conventional designs had achievable sample-size requirements for estimating the cover of common species and grouped growth forms within a $50 \%$ relative margin of error $(\mathrm{MoE})$, the sample sizes required to accurately estimate cover of common species with greater precision (e.g., within $25 \%$ of the observed mean) exceed those commonly used (32, 28, and 54 for DTs, MWPs, or PLITs, respectively). In addition, among-design differences in sample-size requirements become amplified with increased precision; for example to estimate cover within $25 \%$ of the observed mean, PLITs required nearly twice the replication as did MWPs or DTs. Investigations that require a precise $\mathrm{MoE}$ for common species or growth forms will require sampling efforts in excess of what is commonly done.

For less common species, all conventional designs required prohibitively high sample sizes $(118,62$, and 75 DTs, MWPs, or PLITs, respectively) to estimate cover

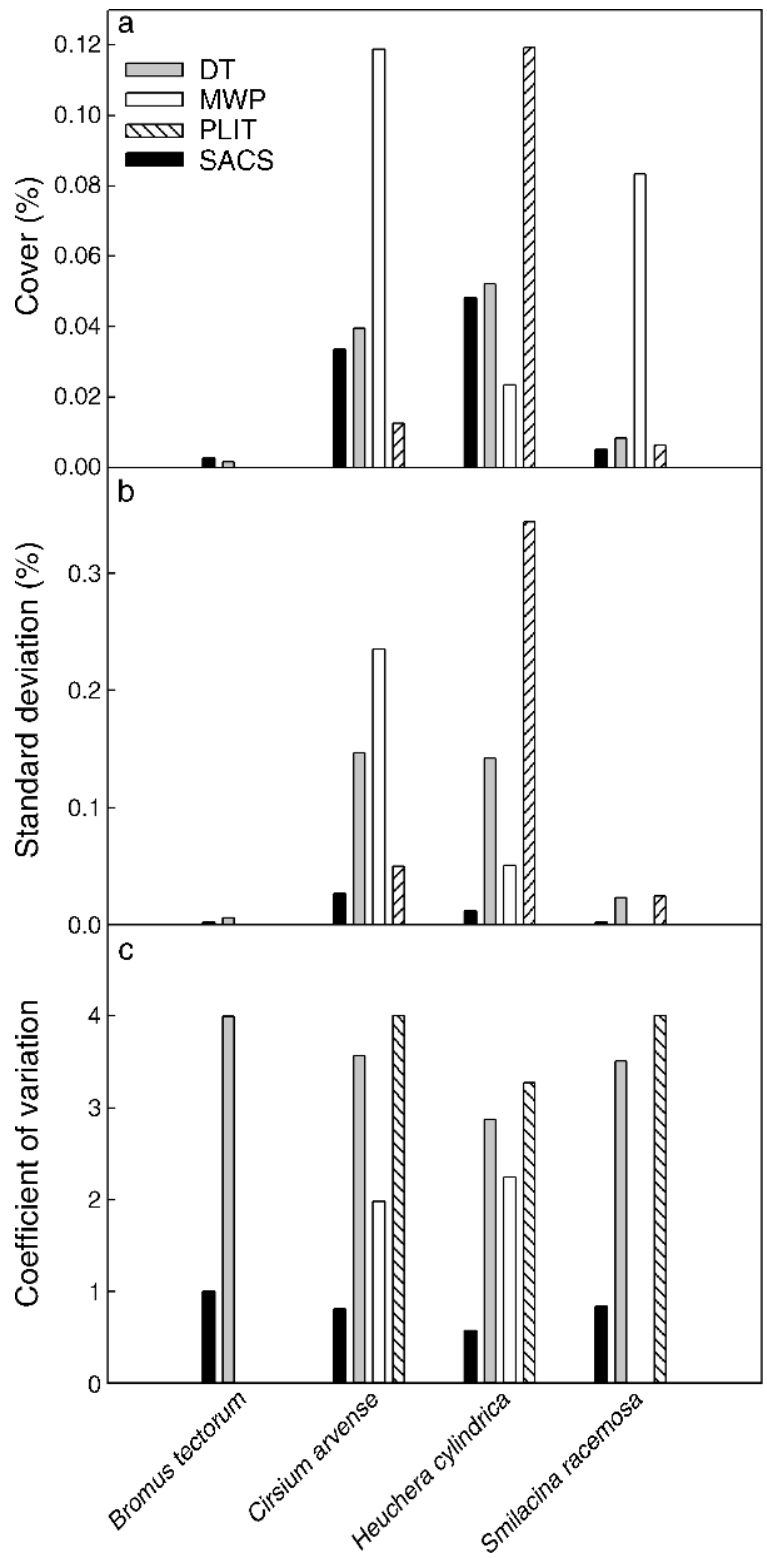

FIG. 4. Sampling results for the four species sampled using strip adaptive cluster sampling (SACS). (a) Percent cover, (b) within-stand standard deviation, and (c) coefficient of variation for the four species sampled using SACS as well as the three multispecies designs (DT, MWP, and PLIT; see Fig. 3 legend for sampling abbreviations). Coefficient of variation for Bromus tectorum and Cirsium arvense is based on data only from the thinned-and-burned stands; these species were absent or present on only one control stand.

even within a $50 \%$ relative MoE. Similarly, to estimate cover of grouped nonnative plants to within $50 \%$ of their observed mean required sample sizes of 60,73 , or 29 DTs, MWPs, or PLITs, respectively. However, SACS required 9-17 times fewer replicates than did conventional designs, due to its comparatively low standard deviations. For instance, the sample size required to estimate Cirsium arvense, an invasive nonnative plant, 


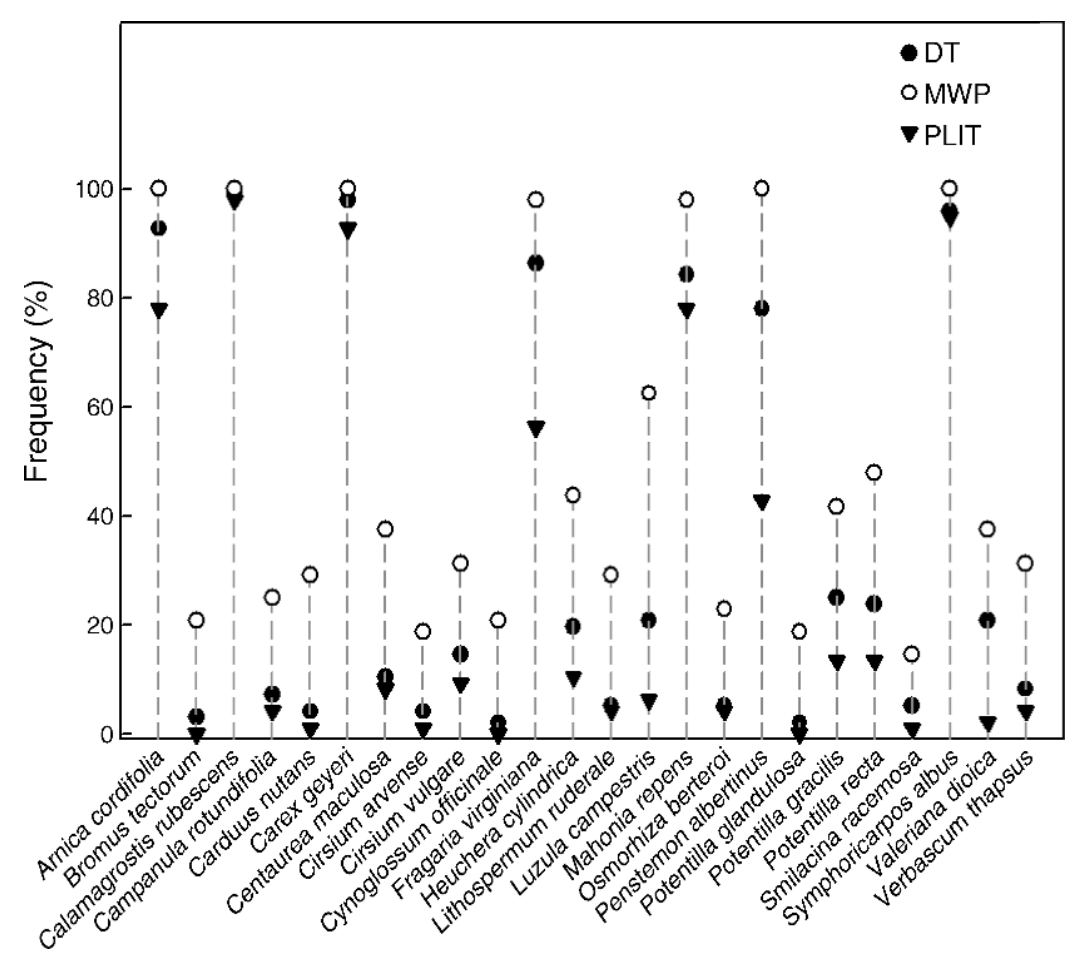

FIG. 5. For each of the 24 focal species, mean within-stand frequency (percentage of transects or plots within a stand containing the focal species) for each sampling design (see Fig. 3 legend for sampling abbreviations).

was $>5$ times greater for MWPS and 20 times greater for DTs or PLITs than it was for SACS. Thus, if estimating cover of individual less common species is a goal, the only reliable design of the ones tested is SACS.

The unequal number of stands included for the sample-size and time-to-sample calculations complicates inference about the reliability of designs for less common species. We calculated sampling-effort requirements only from stands where a focal species was detected; for these analyses, the exclusion of stands in which a focal species was not detected by a design was necessary because otherwise standard deviations would equal 0 and, consequently, sample-size requirements would be unrealistically low. However, this procedure may explain our finding of smaller required sample sizes for PLITs than for DTs, for less common species. PLITs detected less common species in fewer stands than did DTs; thus, DT sample-size calculations included stands with high variances in cover that were excluded from PLIT sample-size analysis. For less common species, the greater detection capability of DTs may have biased sample-size requirements against this design.

Although designs that employ ocular estimation of foliar cover (i.e., DTs and MWPs) required smaller sample sizes than did PLITs, they required more time to reliably sample grouped vegetation variables, as well as common and less common plants. The relatively fast time-to-sample with PLITs more than compensated for the larger sample sizes they required to estimate mean cover, with the caveat that PLITs had low rates of species detection (which is a serious flaw for less common species). DTs required less time to accurately estimate the cover of grouped vegetation variables and common species than did MWPs, while MWPs required marginally less time to sample less common species than did DTs. These results are consistent with previous investigations in ponderosa pine-dominated forests (Korb et al. 2003, Abella and Covington 2004) and

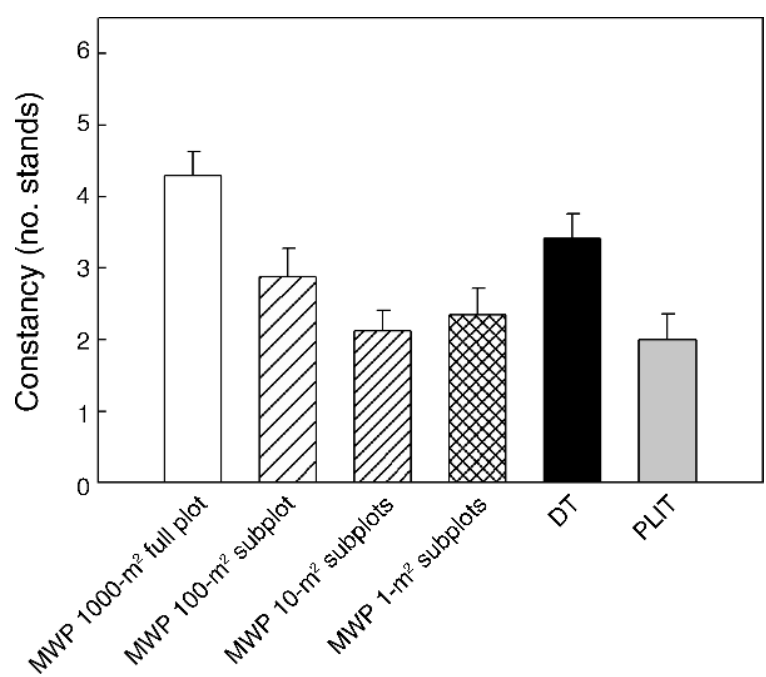

FIG. 6. Mean constancy (number of stands in which species was detected, mean + SE) of less common species for each sampling design (see Fig. 3 legend for sampling abbreviations). 

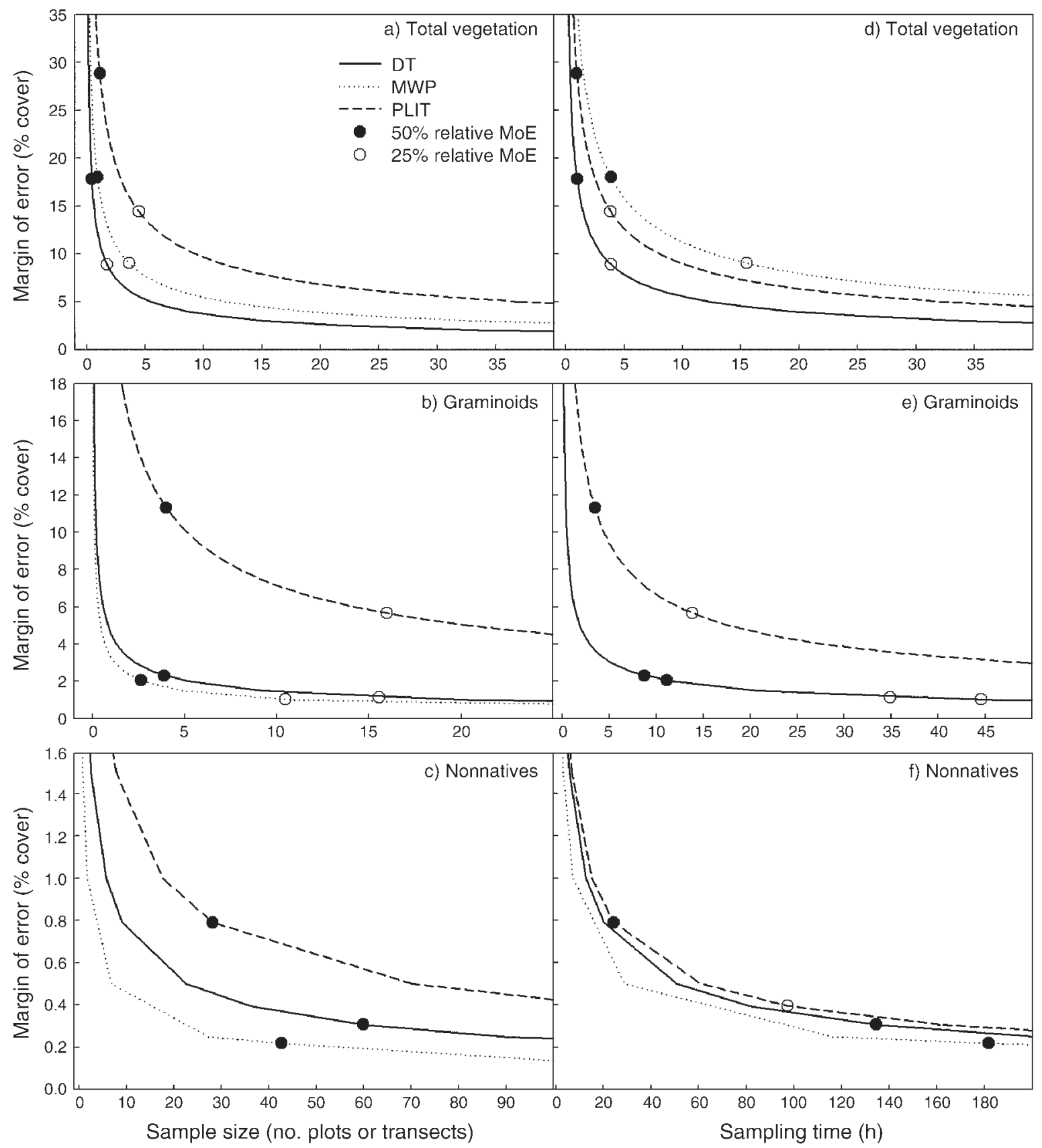

FIG. 7. A comparison of the margin of error (MoE; see Table 1) for (a-c) sample size and (d-f) time required to estimate cover of $(a, d)$ total vegetation, (b, e) graminoids, (c, f) and nonnative plants for each sampling design (see Fig. 3 legend for sampling abbreviations). In panel (e), traces for DTs and MWPs cannot be visually distinguished because they entirely overlap.

grassland ecosystems (Symstad et al. 2008) that have found PLITs take significantly less time than do designs that require ocular estimation.

\section{Practical considerations when implementing SACS}

This is one of the first field applications of adaptive sampling for plant species (but see Acharya et al. 2000 and Phillippi 2005). The fact that it resulted in lower variances and greater sampling efficiency suggests it may be a promising method for sampling understory plants that are locally rare and aggregated. However, there are several practical matters to consider when applying this design. The most obvious limitation is that SACS is meant for sampling one rather than multiple species and, therefore, cannot be used to characterize plant community composition. Thus, species that warrant use of this design should be of management or scientific concern, such as highly invasive nonnatives or rare natives. In 

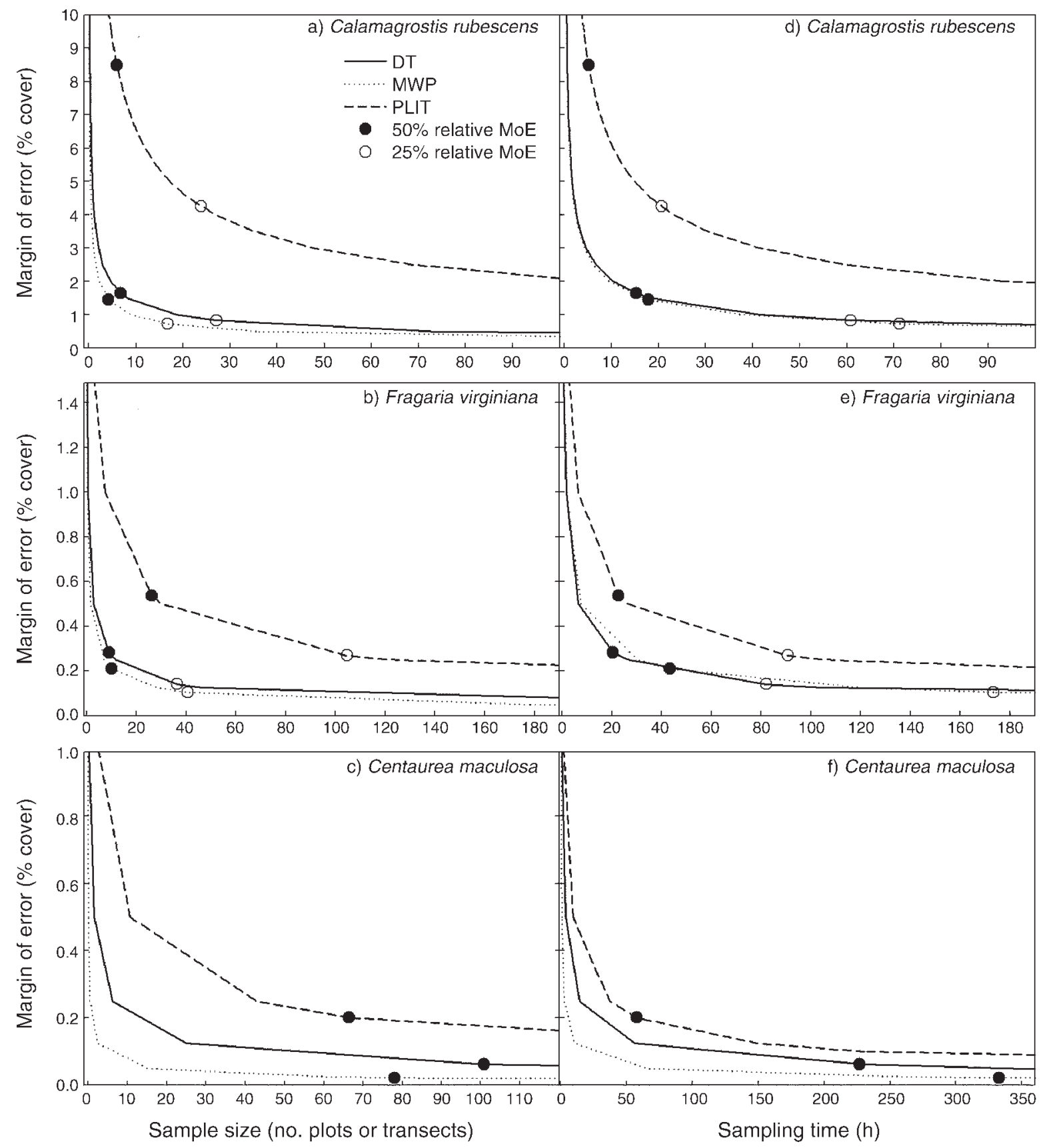

FIG. 8. A comparison of the margin of error for $(a-c)$ sample size and $(d-f)$ time required to estimate percent cover of $(a, d) a$ common graminoid (Calamagrostis rubescens), (b, e) a common, but low-cover forb (Fragaria virginia), and (c, $\mathrm{f}$ ) a less common nonnative forb (Centaurea maculosa) for each of the three multispecies designs (see Fig. 3 legend for sampling abbreviations). See Appendix B for results for all 24 focal species and for species sampled with SACS.

addition, species sampled with SACS must have aggregated distributions in order to benefit from its adaptive nature (Thompson 2002, Brown 2003).

Other factors that must be taken into consideration prior to selecting an adaptive design include that design efficiency is greatly affected by the critical value, adaptive network arrangement, arrangement of primary units, and unit (quadrat) size (Thompson 2002, Brown
2003). For instance, while larger quadrat sizes could enhance efficiency for some species, estimating cover of understory plants in quadrats greater than $1 \mathrm{~m}^{2}$ could increase measurement error or be difficult to implement where trees and other vegetation are abundant. The high potential for trampling focal species and surrounding vegetation is another concern. As units are added to the initial strip (or neighborhood quadrats), the network 
TABLE 1. Comparison of sampling designs by sample size and length of time required for estimation of mean cover within $50 \%$ and $25 \%$ of the observed mean cover ( $90 \%$ confidence) for common and less common species of forest understory plants in western Montana, USA.

\begin{tabular}{|c|c|c|c|c|}
\hline \multirow{2}{*}{$\begin{array}{l}\text { Sampling } \\
\text { design }\end{array}$} & \multicolumn{2}{|c|}{$\begin{array}{c}\text { Sample size } \\
\text { (no. plots or transects) }\end{array}$} & \multicolumn{2}{|c|}{ Sampling time (h) } \\
\hline & $50 \%$ & $25 \%$ & $50 \%$ & $25 \%$ \\
\hline \multicolumn{5}{|c|}{ Common species } \\
\hline $\begin{array}{l}\text { DT } \\
\text { MWP } \\
\text { PLIT }\end{array}$ & $\begin{array}{r}9(1) \\
8(1) \\
14(4)\end{array}$ & $\begin{array}{l}32(4) \\
28(5) \\
54(16)\end{array}$ & $\begin{array}{l}19(2) \\
31(5) \\
12(3)\end{array}$ & $\begin{array}{r}71(8) \\
119(21) \\
46(14)\end{array}$ \\
\hline \multicolumn{5}{|c|}{ Less common species§ } \\
\hline $\begin{array}{l}\text { DT } \\
\text { MWP } \\
\text { PLIT } \\
\text { SACS }\end{array}$ & $\begin{array}{r}118(16) \\
62(7) \\
75(16) \\
7(2)\end{array}$ & $\begin{array}{c}468(63) \\
251(25) \\
254(57) \\
27(7)\end{array}$ & $\begin{array}{c}264(36) \\
246(32) \\
61(14) \\
6(1)\end{array}$ & $\begin{array}{c}1051(142) \\
1006(120) \\
209(50) \\
20(5)\end{array}$ \\
\hline
\end{tabular}

Notes: Values are means with SE in parentheses. Sampling designs are: DT, Daubenmire transect; MWP, modified Whittaker transect; PLIT, point-line intercept transects; and SACS, strip adaptive cluster sampling. For common species, $n=$ 7 species for each sampling design. For less common species, $n=$ 17 species for multispecies designs and $n=4$ for SACS.

expands outwards; thus, care must be taken not to trample plants not yet sampled. Finally, defining protocols (e.g., critical values, networks, shape of initial units) for adaptive sampling is inherently species and location specific; the lack of standard protocols makes this design more difficult to implement relative to conventional designs.

We found little evidence of between-environment (treated vs. control) differences in the efficacy of sampling designs. In our investigation we only tested for effect of environment on the within-stand standard deviations of cover. However, in a companion investigation, Abrahamson (2009) found that none of the three conventional designs showed significant between-environment differences in cover for any species abundant enough to be analyzed. In combination, these findings suggest that the performance of sampling designs was generally not dependent on the post-treatment environment.

\section{Conclusion}

Selection of sampling strategies for understory plants must be driven by specific research or sampling objectives. A design that is most efficient for characterizing community composition may not be appropriate for estimating cover of individual species or species grouped by growth form. While all three multispecies sampling designs were capable of estimating the cover of common species and species grouped by growth form with reasonable sample sizes (albeit different time taken to sample), these designs require prohibitively high sample sizes to estimate cover of less common species or nonnative species as a group. This is especially troublesome, given that less common species comprise the majority of the diversity in forested systems and are frequently of management concern, whether they are rare natives or invading nonnative plants. The low cover and relatively high variability of these species makes it difficult both to precisely estimate their cover and to detect differences in cover among environments with different management histories. We found that sampling with SACS offers tremendous gains in precision for sampling individual target species, in comparison to multispecies designs. Consequently, if a primary research objective is to efficiently estimate cover of a limited number of less common and aggregated species of concern, SACS may be the most appropriate approach.

\section{ACKNOWLedgments}

We are grateful to Ragan Callaway and two anonymous reviewers for valuable comments on a previous version of this manuscript. Haley Wiggins provided assistance with data collection. This work was supported by $07-10$ Montana NSF EPSCoR Grant: Award number EPS-0701906.

\section{Literature Cited}

Abella, S. R., and W. W. Covington. 2004. Monitoring an Arizona ponderosa pine restoration: sampling efficiency and multivariate analysis of understory vegetation. Restoration Ecology 12:359-367.

Abrahamson, I. A. 2009. Assessing the performance of sampling designs for measuring abundance of understory plants after forest restoration. Thesis. University of Montana, Missoula, Montana, USA.

Acharya, B., G. Bhattarai, A. de Gier, and A. Stein. 2000. Systematic adaptive cluster sampling for the assessment of rare tree species in Nepal. Forest Ecology and Management 137:65-73.

Baker, W. L., T. T. Veblen, and R. L. Sherriff. 2007. Fire, fuels, and restoration of ponderosa pine-Douglas fir forests in the Rocky Mountains, USA. Journal of Biogeography 34:251269.

Barbier, S. 2008. Influence of tree species on understory vegetation diversity and mechanisms involved: a critical review for temperate and boreal forests. Forest Ecology and Management 254:1-15.

Barnett, D. T., and T. J. Stohlgren. 2003. A nested-intensity design for surveying plant diversity. Biodiversity and Conservation 12:255-278.

Bonham, C. D. 1989. Measurements for terrestrial vegetation. John Wiley and Sons, New York, New York, USA.

Brown, J. A. 2003. Designing an efficient adaptive cluster sample. Environmental and Ecological Statistics 10:95-105.

D'Antonio, C. M., and P. M. Vitousek. 1992. Biological invasion by exotic grasses, the grass/fire cycle, and global change. Annual Review of Ecology and Systematics 23:6387.

Daubenmire, R. 1959. A canopy-coverage method of vegetation analysis. Northwest Science 33:43-64.

Floyd, D. A., and J. E. Anderson. 1987. A comparison of three methods for estimating plant cover. Journal of Ecology 75: 221-228.

Fulé, P. Z., D. C. Laughlin, and W. W. Covington. 2005. Pineoak forest dynamics five years after ecological restoration treatments, Arizona, USA. Forest Ecology and Management 218:129-145.

Glatzle, A., A. Mechel, and M. E. Moore. 1993. Botanical components of annual Mediterranean grassland as determined by point intercept and clipping methods. Journal of Range Management 46:271-274. 
Goslee, S. C. 2006. Behavior of vegetation sampling methods in the presence of spatial autocorrelation. Plant Ecology 187: 203-212.

Gregoire, T. G., and H. T. Valentine. 2008. Sampling strategies for natural resources and the environment. Taylor and Francis Group, Boca Raton, Florida, USA.

Greig-Smith, P. 1983. Quantitative plant ecology. University of California Press, Berkeley, California, USA.

Griffis, K. L., J. A. Crawford, M. R. Wagner, and W. H. Moir. 2001. Understory response to management treatments in northern Arizona ponderosa pine forests. Forest Ecology and Management 146:239-245.

Halpern, C. B., D. McKenzie, S. A. Evans, and D. A. Maguire. 2005. Initial responses of forest understories to varying levels and patterns of green-tree retention. Ecological Applications 15:175-195.

Hitchcock, C. L., and A. Cronquist. 1973. Flora of the Pacific Northwest. University of Washington Press, Seattle, Washington, USA.

Huebner, C. D. 2007. Detection and monitoring of invasive exotic plants: a comparison of four sampling methods. Northeastern Naturalist 14:183-206.

Knapp, E. E., and J. E. Keeley. 2006. Heterogeneity in fire severity within early season and late season prescribed burns in a mixed-conifer forest. International Journal of Wildland Fire 15:37-45.

Knapp, E. E., D. W. Schwilk, J. M. Kane, and J. E. Keeley. 2007. Role of burning season on initial understory vegetation response to prescribed fire in a mixed conifer forest. Canadian Journal of Forest Research 37:11-22.

Korb, J. E., W. W. Covington, and P. Z. Fulé. 2003. Sampling techniques influence understory plant trajectories after restoration: an example from ponderosa pine restoration. Restoration Ecology 11:504-515.

Metlen, K. L., and C. E. Fiedler. 2006. Restoration treatment effects on the understory of ponderosa pine/Douglas-fir forests in western Montana, USA. Forest Ecology and Management 222:355-369.

Miller, T., D. Mladenoff, and M. Clayton. 2002. Old-growth northern hardwood forests: spatial autocorrelation and patterns of understory vegetation. Ecological Monographs 72:487-503.

Moora, M., T. Daniell, H. Kalle, J. Liira, K. Pussa, E. Roosaluste, M. Opik, R. Wheatley, and M. Zobel. 2007. Spatial pattern and species richness of boreonemoral forest understorey and its determinants - a comparison of differently managed forests. Forest Ecology and Management 250: 64-70.

Mueller-Dombois, D., and H. Ellenberg. 1974. Aims and methods of vegetation ecology. John Wiley and Sons, New York, New York, USA.

Nelson, C. R., and C. B. Halpern. 2005. Edge-related responses of understory plants to aggregated retention harvest in the Pacific Northwest. Ecological Applications 15:196-209.

Nelson, C. R., C. B. Halpern, and J. Agee. 2008. Thinning and burning have little effect on native plant communities but promote low-level invasion by nonnative plants. Ecological Applications 18:762-770.

Nimlos, T. J. 1986. Soils of Lubrecht Experimental Forest. Publication number 44, Montana Forest and Conservation Experiment Station, Missoula, Montana, USA.

Ott, R. L., and M. Longnecker. 2001. An introduction to statistical methods and data analysis. Fifth edition. Wadsworth Group, Pacific Grove, California, USA.

Philippi, T. 2005. Adaptive cluster sampling for estimation of abundances within local populations of low-abundance plants. Ecology 86:1091-1100.

Rejmanek, M. 2000. Invasive plants: approaches and predictions. Austral Ecology 25:497-506.

Scheller, R. 2002. Understory species patterns and diversity in old-growth and managed northern hardwood forests. Ecological Applications 12:1329-1343.

Shmida, A. 1984. Whittaker's plant diversity sampling method. Israel Journal of Botany 33:41-46.

SPSS. 2006. SPSS for Windows, version 15.0. SPSS, Chicago, Illinois, USA.

Stohlgren, T. J. 2007. Measuring plant diversity. Oxford University Press, Inc., New York, New York, USA.

Stohlgren, T. J., K. A. Bull, and Y. Otsuki. 1998. Comparison of rangeland vegetation sampling techniques in the Central Grasslands. Journal of Range Management 51:164-172.

Stohlgren, T. J., M. B. Falkner, and L. D. Schell. 1995. A modified-Whittaker nested vegetation sampling method. Vegetatio 117:113-121.

Symstad, A. J., C. L. Wienk, and A. D. Thorstenson. 2008. Precision, repeatability, and efficiency of two canopy-cover estimate methods in northern Great Plains vegetation. Rangeland Ecology and Management 61:419-429.

Thompson, S. K. 1991. Adaptive cluster sampling: designs with primary and secondary units. Biometrics 43:1103-1115.

Thompson, W. L. 2002. Sampling. John Wiley and Sons, New York, New York, USA.

Thompson, W. L. 2004. Sampling rare or elusive species: concepts, designs, and techniques for estimating population parameters. Island Press, Washington, D.C., USA.

Turner, M. G., W. H. Romme, R. H. Gardner, and W. W. Hargrove. 1997. Effects of fire size and pattern on early succession in Yellowstone National Park. Ecological Monographs 67:411-433.

USDA NRCS [National Resource Conservation Service]. 2008. The PLANTS database. National Plant Data Center, Baton Rouge, Louisiana, USA. 〈http://www.plants.usda.gov〉

USDI National Park Service. 2003. Fire monitoring handbook. Fire Management Program Center, National Interagency Fire Center, Boise, Idaho, USA.

Wienk, C. L., C. H. Sieg, and G. R. McPherson. 2004. Evaluating the role of cutting treatments, fire and soil seed banks in an experimental framework in ponderosa pine forests of the Black Hills, South Dakota. Forest Ecology and Management 192:375-393.

\section{APPENDIX A}

A figure showing the location of sampling units within each treatment (Ecological Archives A021-026-A1).

\section{APPENDIX B}

A table showing observed mean cover, constancy, and required sample size for each sampling design, and time-to-sample estimates for grouped vegetation variables and for individual species (Ecological Archives A021-026-A2).

\section{APPENDIX C}

Proof of unbiasedness of the SACS estimator (Ecological Archives A021-026-A3). 